\title{
Innovation in a Regulated Environment: Why Do We Need it and How Are We Going to Get It?
}

\author{
Tom Kaszas \\ Ministry of the Environment and Climate Change \\ Toronto, Canada
}

Today's environmental engineering challenges have moved beyond the traditional. Traditional environmental engineering approaches were by a large developed to address eutrophication and aesthetic concerns, and focussed on point source discharges and macro contaminants such as pathogenic bacteria (coliforms), oxygen depleting organic matter and nutrients. Today's environmental challenges are more complex and include contaminants of emerging concern (some of which are the products of our conventional treatment approaches). Increasing densification of urban centres provides both challenges and opportunities for distributed treatment infrastructure, stormwater management and water reuse. How can we stimulate the innovation we need to solve these complex challenges and seize these opportunities within a regulatory framework that was designed with the conventional in mind? 